\title{
Response of Circulation and Heat Transport in the North Atlantic to Changes in Thermohaline Forcing in Northern Latitudes: A Model Study
}

\author{
Ralf Dóscher, Claus W. Bóning, and Peter Herrmann \\ Institut für Meereskunde, Kiel, Germany
}

(Manuscript received 30 March 1993, in final form 25 February 1994)

\section{ABSTRACT}

\begin{abstract}
To avoid an explicit simulation of the overflows across the Greenland-Scotland ridge, many models of the large-scale ocean circulation seek to include the net effect of the inflowing dense water masses by restoring temperature and salinity near the ridge to observed conditions. In this paper the authors examine the effect of different datasets for the northern restoring condition in two versions, eddy resolving and non-eddy resolving, of the model of the North and equatorial Atlantic that has been developed in recent years as a Community Modeling Effort for WOCE. It is shown that the use of smoothed climatological felds of temperature and salinity south of the Denmark Strait leads to strong deficiencies in the simulation of the deep flow field in the basin. A switch to actual hydrographic data from the Denmark Strait ignites a rapid dynamic response throughout the Nortb Allantic, affecting the transport and vertical structure of the deep western boundary current and, by virtue of the JEBAR effect, the transport of the horizontal gyres. Meridional overturning and northward heat transport, too weak in the cases with climatological boundary conditions, increase to more realistic levels in the subtropical North Atlantic.

The initial response to switches in the high-latitude thermohaline forcing is mediated by fast waves along the western boundary, leading to changes in the deep western boundary current in low latitudes after about two years in the non-eddy-resolving case. The initial timescale depends on the horizontal grid spacing of the model; in the high-resolution case, the first signal reaches the equator in a few months. The adjustment to a new, dynamic quasi equilibrium involves Kelvin waves along the equator and Rossby waves in the interior and is attained in less than two decades throughout the North Atlantic. It is suggested that these fast dynamic adjustment processes could play an important role in possible fluctuations of the thermohaline circulation, or transitions between different equilibrium states of the coupled ocean-atmosphere system, and may have determined the timescale of the observed climatic transitions before and during the last deglaciation.
\end{abstract}

\section{Introduction}

The meridional volume transport of the thermohaline cell in the North Atlantic is of great interest in the context of large-scale circulation studies, because it represents a dominant factor for poleward transport of heat. Under present climate conditions, the main pattern of the overturning cell is given by the southward spreading of North Atlantic Deep Water (NADW) originating from deep winter convection in the Labrador Sea and north of Iceland. The bulk of NADW is carried southward by deep western boundary currents (DWBC) along the American continental slope (Fine and Molinari 1988; Molinari et al. 1992). Deep water formation rates and the magnitude of the meridional overturning are under debate. Evidence from water mass analysis and hydrographic sections (Gordon 1986; Schmitz and Richardson 1991; Roemmich and

Corresponding author address: Dr. Ralf Döscher, Institut für Meereskunde an der Universität Kiel, Düsternbrooker Weg 20, D2300 Kiel 1, Germany.
Wunsch 1985) indicates a transport of the NADW cell of 13-20 Sv ( $\mathrm{Sv} \equiv 10^{6} \mathrm{~m}^{3} \mathrm{~s}^{-1}$ ), associated with a northward heat transport in the subtropical North Atlantic at $24^{\circ} \mathrm{N}$ of $1.2 \pm 0.3 \mathrm{PW}$ (Hall and Bryden 1982).

Numerical models of the wind-driven and thermohaline circulation very often had problems in reproducing its observed magnitude. A too weak southward transport of NADW, especially of lower NADW, was noted in various model studies using realistic bathymetry and forcing, including the Atlantic model of Sarmiento (1986), the experiments within the World Ocean Circulation Experiment (WOCE) Community Modeling Effort (CME) (e.g., see Bryan and Holland 1989; Böning et al. 1991), and the global model of Semtner and Chervin (1992). Each of these models had a closed wall near $65^{\circ} \mathrm{N}$ and the effect of exchange with the Nordic Seas was taken into account by restoring the model temperature and salinity fields near this boundary toward the observed, climatological values.

The factors controlling the magnitude of meridional overturning and heat transport in such model simu- 
lations are not fully understood yet. Using restoring boundary conditions at the surface and lateral open boundaries excludes the possibility of multiple equilibrium states for the thermohaline circulation (Marotzke and Willebrand 1991; Weaver and Sarachik 1991).

The thermodynamic equilibrium state under given restoring conditions was shown to depend critically on model factors like diapycnal diffusivity (Bryan 1987; Colin de Verdiére 1988) and the numerical advection scheme (Gerdes et al. 1991). Maier-Reimer et al. (1993) demonstrated the sensitivity of the overturning to changes in the surface heat flux forcing. However, it is not yet clear what factors essentially control the results of high-resolution models, as used in the CME or in Semtner and Chervin (1992), that are far from thermodynamic equilibrium: after an integration period of several decades, the hydrographic fields in the deep ocean interior in these models have not drifted far away from the initial conditions given by the climatology of Levitus (1982).

The thermodynamic spinup of a primitive equation ocean model from a state of rest, and given hydrographic conditions, can be characterized by several stages with very different timescales. The initial geostrophic adaptation process accomplished by internal gravity waves during the first days and weeks is followed by a dynamic response to the atmospheric forcing on a timescale given by the travel time of baroclinic Rossby waves through the basin. During this initial dynamic adjustment phase-that is, the first 10-20 years-the mean density structure below the thermocline remains close to the start conditions, except for regions of strong currents, for example, near the western boundary, or regions with deep winter convection. This state will be called here "dynamic quasi equilibrium." The thermohaline adjustment proceeds on a much longer timescale, dictated by the slow diffusive and advective processes in the deep ocean interior. An equilibrium between the thermohaline fluxes at the surface and lateral boundaries and the ocean circulation will be reached after several hundreds or thousands of years.

The dynamic part of the spinup of the deep ocean circulation had been examined by Kawase (1987) in an inspiring work using a two-layer model of a rectangular ocean basin without topography: The response signal to deep-water production in the subpolar ocean is carried by baroclinic Kelvin waves equatorward along the western boundary, then along the equator and later poleward along the eastern boundary. From there, long Rossby waves are radiated, setting up the deep interior poleward flow consistent with the dynamical ideas of Stommel and Arons (1960) (in the limit of negligible damping of long Rossby waves). In that idealized model the spinup takes about 200 days. This problem was resumed by Suginohara and Fukasawa (1988) using a six-level, primitive equation model, and Kawase et al. (1992) using a model with high resolution both in the horizontal and vertical direction. Similar adjustment processes were noted in these numerical studies, but the equilibration took several years now, apparently due to the presence of slower baroclinic modes of higher order.

In this paper, we shall use various versions of the CME model to examine the response of the thermohaline circulation in the North Atlantic to quantitative changes in the lateral thermohaline forcing. These questions are especially referred to in this work: How sensitive are the meridional overturning and heat transport to the specification of the northern thermohaline boundary conditions $(\Theta, S)$ in a basin-scale model? What is the effect of a changed thermohaline circulation on the vertically integrated, horizontal circulation? On which timescales does the model respond to a sudden change in the boundary conditions and which processes determine the response timescale? We restrict our considerations to timescales of less than 20 years, wherein we can expect a new dynamic quasi equilibrium. The adaptation to a full thermodynamic equilibrium proceeds on a much longer timescale, which is beyond the scope of this study.

The paper is organized as follows: After a description of the model experiments ( section 2), we will examine the temporal behavior of the deep flow and meridional overturning after sudden changes in the thermohaline forcing (section 3 ). It will be shown that the dynamic response to changes in the subpolar area affects the whole North Atlantic within about 2 years: a timescale already suggested by the idealized models. In section 4, we will compare the different quasi-equilibrium states with respect to the structure of the circulation and the associated heat transports. A summary and conclusions will be given in section 5 .

\section{The model}

The numerical model is based on primitive equations as described by Bryan (1969) and Cox (1984). The specific model configuration was developed by Bryan and Holland (1989) in the WOCE CME. Two versions of this model will be used here: a non-eddyresolving version with a horizontal resolution of $1^{\circ}$ in latitude and $1.2^{\circ}$ in longitude, and an eddy-resolving version with a resolution of $1 / 3^{\circ}$ by $0.4^{\circ}$. The model domain encompasses the Atlantic Ocean between $15^{\circ} \mathrm{S}$ and $65^{\circ} \mathrm{N}$, with realistic bathymetry. The northern and southern boundaries are closed to normal flow, and there is also no flow into or out of the Mediterranean Sea. The vertical coordinate is discretisized into $30 \mathrm{lev}-$ els; the vertical grid spacing increases smoothly from $35 \mathrm{~m}$ at the surface to $250 \mathrm{~m}$ below $1000-\mathrm{m}$ depth. The maximum depth is $5500 \mathrm{~m}$.

All model cases described here are forced with the climatological monthly mean wind stresses of Isemer 
and Hasse (1987). The thermohaline circulation is driven by a relaxation of temperature and salinity at the surface and at the northern and southern boundaries. The surface salinity is relaxed to the monthly mean values of Levitus (1982), and the surface temperature to monthly values of "apparent" atmospheric temperature as described by Han (1984). That heat flux formulation implicitly includes such effects as direct solar shortwave radiation and wind speed dependence of the air-sea heat transfer. A surface mixed layer model of Kraus-Turner type is included as a purely vertical process. The model satisfactorily simulates the observed seasonal cycle of heat storage and surface heat flux over the North Atlantic (Böning and Herrmann 1994). Because of the restricted model domain, buffer zones are incorporated at the northern and southern boundary in which potential temperature $(\theta)$ and salinity $(S)$ are restored to observed climatological monthly mean values. The artificial water mass transformations thereby enforced in these zones represent a crude model counterpart to the diapycnic processes taking place outside the model domain, that is, production of the source waters for lower NADW in re-
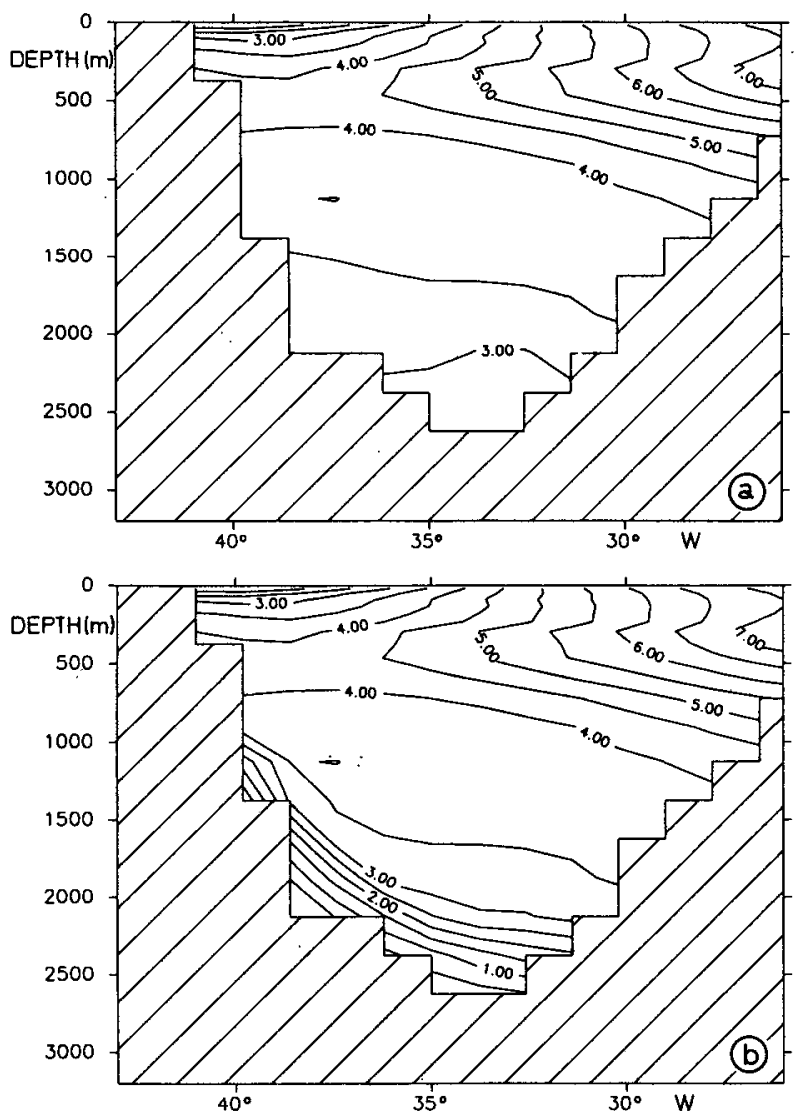

FIG. 1. Potential temperature in the Denmark Strait restoring zone (in ${ }^{\circ} \mathrm{C}$ ) (a) based on Levitus (1982), and (b) with idealized DSOW introduced at the deep western slope region. Contour interval is $0.5^{\circ} \mathrm{C}$.

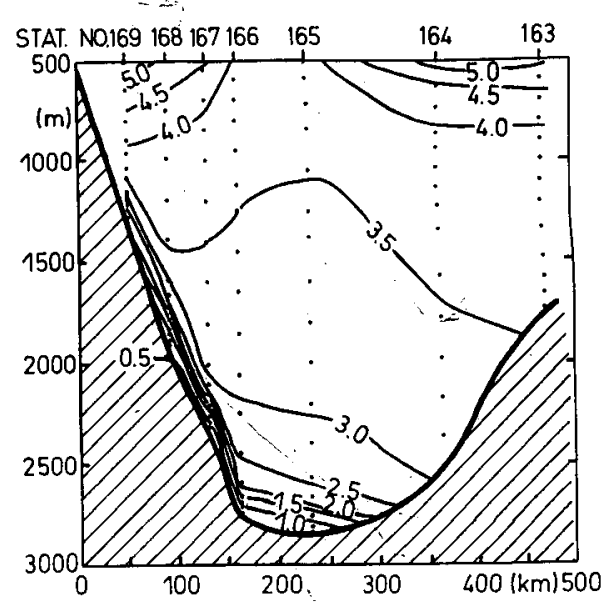

FIG. 2. Observed potential temperature (in ${ }^{\circ} \mathrm{C}$ ) from the TTO section just south of the Denmark Stràit (from $65^{\circ} \mathrm{N}, 35^{\circ} \mathrm{W}$ to $63^{\circ} \mathrm{N}$, $28^{\circ} \mathrm{W}$ ) [ from Smethie and Swift (1989)]

gions north of Iceland, and upwelling of NADW in the global ocean. In previous CME experiments, as in other model studies (e.g., Sarmiento 1986; Semtner and Chervin 1992), the monthly mean values as given by the climatology of Levitus (1982) were used for this restoring. It is important to note that due to the spatial smoothing, which had been necessary in the production of the climatological dataset (Levitus 1982), the signal of Denmark Strait overflow water (DSOW) along the East Greenland continental slope is almost completely lost (Fig. 1a). The dynamic effect of this signal on the structure and magnitude of the thermohaline cell in the North Atlantic provides the main focus of the present experiments.

We have constructed an alternative formulation for the model buffer zone south of the Greenland-Iceland ridge based on an actual observed hydrographic section. The frontal features in that region and the narrow core of DSOW cannot properly be resolved in a $1^{\circ}$ model. The new buffer zone conditions were hence constructed in a somewhat idealized way: based on a single section (Fig. 2; Smethie and Swift 1989), a minimum potential temperature of $0.0^{\circ} \mathrm{C}$ is prescribed at the lower western slope of the Denmark Strait (Fig. 1b). We assume that there is no seasonal cycle in the prescribed DSOW core, consistent with recent observations (Dickson et al. 1990). Away from the Greenland continental slope, the new restoring data are merged with the Levitus climatology, which becomes dominant $200 \mathrm{~km}$ east of the slope and $300 \mathrm{~m}$ above the bottom. The layers above $700 \mathrm{~m}$ are unaffected by the section data, that is, the hydrographic conditions are the same as in the previous experiments. The model boundary zone is located at the southern slope of the Denmark Strait; its depth therefore exceeds the original sill depth of $700 \mathrm{~m}$. 
In each model version the meridional extent of the buffer zone is given by five grid boxes, that is, $5^{\circ}$ in the coarse-resolution cases and $1.67^{\circ}$ in the high-resolution cases. The restoring timescale in the buffer zones varies from 5 days in the first grid cell adjacent to the boundary to 25 days in the fifth grid cell away from the boundary. We make the assumption that the hydrographic conditions of the cold DSOW core, as given in the actual section from the southern slope of the Denmark Strait, do not significantly vary in downstream direction. All model versions use the same coefficients for vertical diffusivity $\left(0.3 \times 10^{-4} \mathrm{~m}^{2} \mathrm{~s}^{-1}\right)$ and viscosity $\left(10^{-3} \mathrm{~m}^{2} \mathrm{~s}^{-1}\right)$. However, different schemes for horizontal friction are adopted for the high- and low-resolution cases. For horizontal diffusion and viscosity a biharmonic scheme with constant coefficient $\left(-2.5 \times 10^{11} \mathrm{~m}^{4} \mathrm{~s}^{-1}\right)$ is used in the high-resolution model. In contrast, a Laplacian lateral friction and isopycnal diffusion is adopted in the coarse-resolution mode;, to account for the mixing effect of mesoscale eddies (Redi 1982; Cox 1987). The coefficients for along isopycnal diffusivity are depth-dependent and vary between $2 \times 10^{3} \mathrm{~m}^{2} \mathrm{~s}^{-1}$ at the surface and 0.5 $\times 10^{3} \mathrm{~m}^{2} \mathrm{~s}^{-1}$ at greater depths with an $e$-folding depth scale of $500 \mathrm{~m}$. To prevent numerical noise, a background lateral diffusivity $\left(10^{2} \mathrm{~m}^{2} \mathrm{~s}^{-1}\right)$ is necessary. A constant eddy coefficient is used for the horizontal viscosity in the coarse-resolution model $\left(10^{4} \mathrm{~m}^{2} \mathrm{~s}^{-1}\right)$.

The outline of the model experiments is as follows: The spinup of the coarse-resolution model started with the Levitus January temperatures and salinities; a restoring to climatological $\theta$ and $S$ was used in the buffer zones. After 50 years of integration $\left(t_{0}\right)$, several experiments were started, differing in thermohaline forcing. In the reference case

$\mathrm{C} 1$. the climatological conditions in the northern buffer zone were retained.

\section{In experiment}

C2. the buffer zone condition was replaced by the new condition based on the actual section data. This case, integrated over a period of 25 years, will provide the main focus of our analysis. The temporal behavior of the meridional overturning in this "spinup" experiment is complemented by a "spindown" experiment

C3. in which production of deep water in the subpolar North Atlantic was drastically reduced, by limiting wintertime surface cooling to minimum temperatures of $7^{\circ} \mathrm{C}$, and changing the restoring in the northern buffer zone to August values above $700 \mathrm{~m}$. Below that depth, the restoring was omitted.

These coarse-resolution cases are complemented by two experiments with the high-resolution $\left(1 / 3^{\circ}\right) \mathrm{CME}$ model. The initial experiment with that model at NCAR (Bryan and Holland 1989) was a 25-year simulation starting from the temperature and salinity fields of Levitus (1982). Based on this initial spinup, a number of model experiments has been performed both at the National Center for Atmospheric Research (NCAR) and the Institut für Meereskunde (If M), Kiel, mainly aimed at the model's sensitivity to resolution, friction, and wind forcing; for an overview the reader is referred to Bryan et al. (1994). For the present study,

Experiment 4 described in Böning and Herrmann (1994) serves as a reference case, with climatological restoring in the northern buffer zone, analogous to experiment $\mathrm{C} 1$.

The high-resolution equivalent to experiment $\mathrm{C} 2$, represented by

Experiment 6 in the sequence of the Kiel CME experiments, includes the actual section data in a similar manner as shown in Fig. 1b. With this buffer zone the model was integrated for a period of 14 years.

\section{Temporal behavior of deep circulation and meridional overturning}

The zonally integrated meridional volume transport ("overturning") and the northward heat transport are integral representations of the circulation in the meridional-vertical plane, which may serve as indicators of large-scale thermohaline circulation changes. The streamfunction $\Phi$ of the meridional volume transport is given by

$$
\begin{array}{r}
\Phi_{z}=-\int_{\lambda_{\text {east }}}^{\lambda_{\text {west }}} v a \cos \varphi d \lambda \\
a^{-1} \Phi_{\varphi}=\int_{\lambda_{\text {east }}}^{\lambda_{\text {west }}} w a \cos \varphi d \lambda,
\end{array}
$$

where $v$ and $w$ are meridional and vertical velocities, $a$ is the earth's radius and $\varphi$ and $\lambda$ are latitude and longitude. The northward heat transport $Q$ is the vertical and zonal integral of the meridional heat advection and diffusion (Bryan 1962):

$Q=\rho_{0} c_{p} \int_{\lambda_{\text {east }}}^{\lambda_{\text {west }}} \int_{-H(\lambda)}^{0}\left(v T-A_{H} \nabla T\right) a \cos \varphi d z d \lambda$.

The temporal behavior of the maximum overturning and heat transport at selected latitudes is shown in Figs. 3 and 4 for cases $\mathrm{C} 1, \mathrm{C} 2$, and $\mathrm{C} 3$. The maximum overturning is associated with the major deep cell centered around $1500 \mathrm{~m}$ (see section 4, Fig. 8a). A running mean filter of 1-year length is applied to the time series to reduce noise due to the seasonally varying wind field. The temporal change of the meridional overturning in the reference run $\mathrm{Cl}$ is small after 50 years of integration. The switch to the new buffer zone condition (C2) results in a strong increase of the transport, with an 


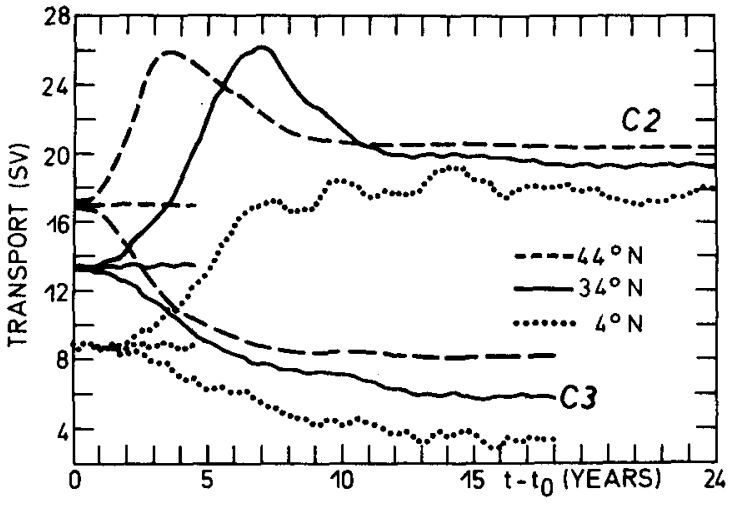

FIG. 3. Maximum of the zonally integrated volume transport streamfunction, in the depth range of the major deep cell, at selected latitudes as a function of time, for the coarse-resolution experiments $\mathrm{C} 1$ ( reference case, unlabeled), $\mathrm{C} 2$, and $\mathrm{C} 3$ (a 1-year running mean filter has been applied).

overshooting in midlatitudes. The northernmost curve $\left(44^{\circ} \mathrm{N}\right.$, approximately the latitude of maximum overturning) reaches a maximum after 3 years. At $34^{\circ} \mathrm{N}$ it takes 7 years. More southerly, first maxima are reached after 8 years. Everywhere in the North Atlantic, the meridional overturning adjusts to a new dynamic quasi equilibrium about $10-15$ years after the switch to the new boundary condition. The northward heat transport in experiment $\mathrm{C} 2$ (Fig. 4) shows a similar evolution. At all latitudes, the heat transport settles down to a new, higher value after running through an intermediate maximum. Averaged over all latitudes, there is an enhancement of about $0.2 \mathrm{PW}$. The initial maxima are reached in a time sequence from north to south. The adjustment times are the same as in the overturning signal.

The maximum overturning of the spindown experiment $\mathrm{C} 3$ decreases on a similar timescale as experiment $\mathrm{C} 2$. The transport curves from all latitudes show a smooth decay to lower equilibria without any overshooting. The maximum overturning at $44^{\circ} \mathrm{N}$ is reduced from $17 \mathrm{~Sv}$ to $9 \mathrm{~Sv}$ within 9 years. In middle and lower latitudes, it takes about 13 years to reach a new dynamic quasi equilibrium. The same decay is visible in the heat transport (Fig. 4). Thus, the decadal timescale of the adjustment processes to different stepfunction-like boundary condition changes appears to be a robust feature of the model.

The effect of horizontal resolution on the adjustment process is examined with experiment 6 , the $1 / 3^{\circ}$ model equivalent to the $1^{\circ}$ case $\mathrm{C} 2$ (Fig. 5). The high-resolution experiment has been integrated for only 14 years on account of limited computing capacities. Because of the different reference states (see section 4), the overturning curves of the two experiments shown in Fig. 5 are normalized with the transport at $t_{0}+0.5$ years (the start of the time-filtered time series) to en-

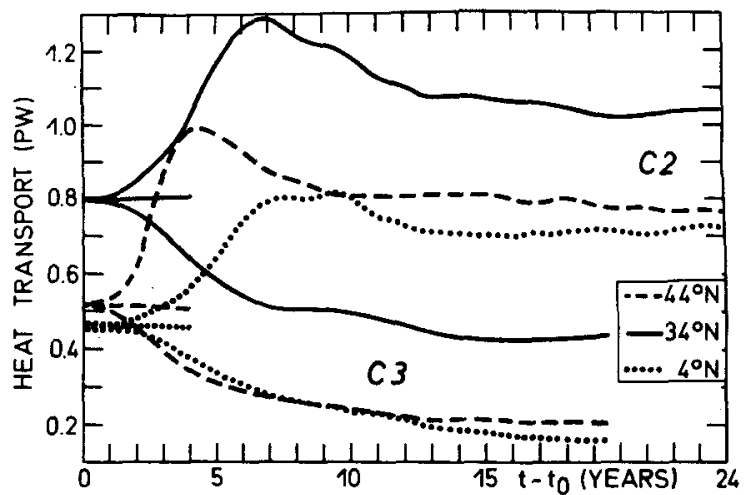

FIG. 4. Northward heat transport at selected latitudes as a function of time for the coarse-resolution experiments $\mathrm{Cl}$ (reference case), $\mathrm{C} 2$, and C3 (a 1-year running mean filter has been applied).

hance comparability. The temporal evolution of the high-resolution case is markedly different during the first years. The initial increase in the overturning occurs much more rapidly, within several months, both in midlatitudes and in the Tropics. The slower initial response in the low-resolution experiment (C2) suggests an influence of grid resolution on the dominant initial processes in the model. The approach toward a new dynamic quasi equilibrium in the high-resolution case is less smooth than in the $1^{\circ}$ model, and characterized by strong interannual fluctuations, especially in the tropics. Due to the rich spectrum of oscillations possible in an eddy-resolving model, it would generally require a multiyear averaging (and longer integration) to define, in a statistical sense, a new equilibrium state. Nevertheless, the $4^{\circ} \mathrm{N}$ curve seems to oscillate around a new mean state after about 8-10 years of integration. Averaged over the last 4-6 years, the overturning in the low latitudes has increased by $70 \%$ to $80 \%$ com-

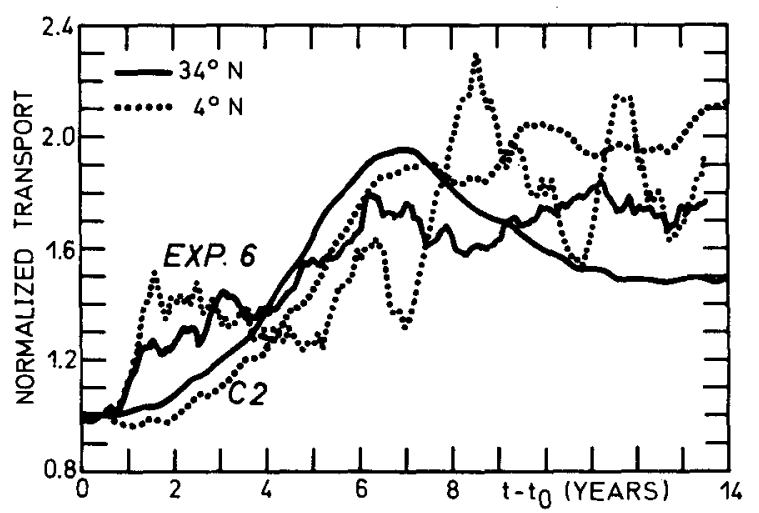

FIG. 5. Initial response of the maximum of the zonally integrated volume transport streamfunction, in the depth range of the major deep cell, at selected latitudes as a function of time for the coarseresolution experiment $\mathrm{C} 2$ and the high-resolution experiment 6 . With a 1-year running mean filter. 
pared to the reference case. Apart from the quantitative difference in the timescale, all three experiments with changed boundary conditions $(\mathrm{C} 2, \mathrm{C} 3$, experiment 6$)$ indicate the presence of a fast initial response process. Even near the equator, we begin to detect a change in the overturning rate of the $1^{\circ}$ model during the second year after the switch to the new boundary condition. As will be seen below, the initial response is confined to the western boundary of the ocean basin and reflects the evolution of the DWBC. A two-year timescale is obviously too short to be caused by advection. The signal at lower latitudes has to be mediated by waves.

In the idealized spinup study of Kawase (1987), the source radiates coastal Kelvin waves propagating south along the deep western boundary and entailing an initial boundary current. After some weeks they reach the equator and are transformed into equatorial Kelvin waves. These become coastal Kelvin waves again, when they encounter the eastern wall. The equatorial and the eastern boundary Kelvin waves radiate long Rossby waves, which set up the deep interior flow and modify the DWBC when reaching the western boundary. The timescale of the complete spinup is about 200 days. Suginohara and Fukasawa (1988) extended the idealized study to a six-level problem and confirmed the principle spinup mechanism of Kawase. Due to the presence of slower baroclinic modes in their six-level model, the adjustment timescale is enhanced to about 10 years.

Here, we are concerned with a stratified model with topography and a rigid lid on top. Possible coastally trapped wave processes include internal Kelvin waves modified by topography, and shelf waves modified by the presence of stratification (Mysak 1980). Both wave modes propagate with the coast to the right (in the Northern Hemisphere). For different shelf forms, there are various combinations of the two parts of these hybrid wave modes. In general, weak stratification results in nearly pure barotropic shelf waves, whereas Kelvinlike modes are established when the stratification strengthens (Huthnance 1978).

The $1^{\circ}$ model cannot properly represent the properties of internal Kelvin-like wave modes. Their first mode offshore scale is given by the internal Rossby radius ( $20-40 \mathrm{~km}$ in the midlatitude North Atlantic). The effective Rossby radius in a discrete numerical model, and thus the offshore scale, widens with increasing lateral viscosity and increasing grid spacing (Hsieh et al. 1983). The zonal grid spacing of the coarse-resolution model at $30^{\circ} \mathrm{N}(115 \mathrm{~km})$ is about three times the Rossby radius. For such a case, Hsieh et al. (1983) found a doubling of the effective Rossby radius and a reduction of the phase speed by a factor of 3 solely due to the resolution. Lateral viscosity, as prescribed by subgrid-scale processes and numerical constraints, reduces the phase speed (Davey et al. 1983). The artificial reduction of the phase speed and the flattening of the offshore structure thus decrease the efficiency of the internal Kelvin-like modes of the hybrid waves in coarse resolution numerical models. In such cases as in the $1^{\circ}$ model the signal will be transmitted more effectively by the less distorted, modified shelf waves running south along the deep western boundary. With higher resolution, the numerical distortion of the offshore structure and the phase speed of the internal modes is much weaker. This could explain the faster initial increase of the overturning in the $1 / 3^{\circ}$ model (experiment 6, Fig. 5). Weakly distorted internal Kelvin-like waves are much faster than shelf waves and can thus cause a faster transfer of information from the northern boundary to the equatorial waveguide in the high-resolution model.

To examine the structure of the response processes taking place in the present model experiments, the signal has to be separated from the strong, wind-induced background variability. In Fig. 6 the response signal in the velocity field of experiment $\mathrm{C} 2$ is extracted by subtracting the corresponding velocities of the reference
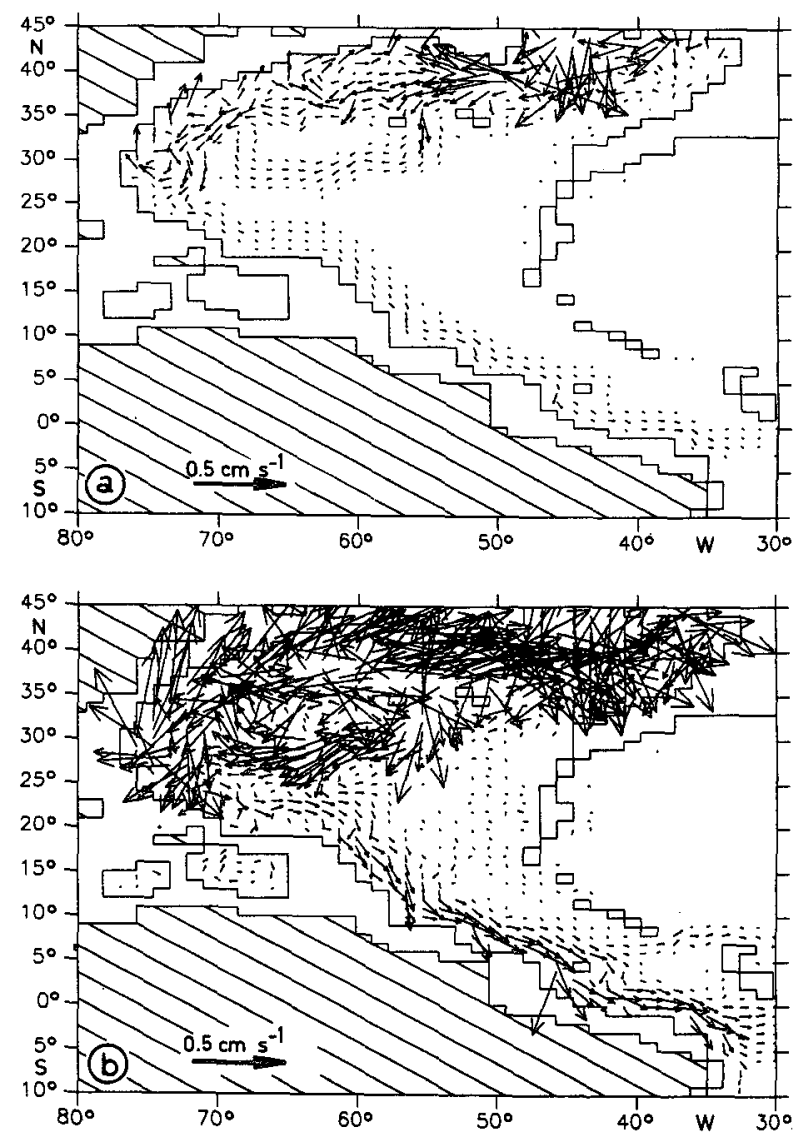

FIG. 6. Velocity anomalies in experiment C2 (difference between $\mathrm{C} 2$ and the reference experiment $\mathrm{Cl}$ ) in $3375-\mathrm{m}$ depth at (a) 1.6 , (b) 2.6 years after the change of the northern boundary condition. Vectors larger than $0.5 \mathrm{~cm} \mathrm{~s}^{-1}$ are set to $0.5 \mathrm{~cm} \mathrm{~s}^{-1}$ to avoid optical confusion. 
case $\mathrm{Cl}$, thereby removing the repetitive, wind-driven seasonal cycle. Similar to the idealized models discussed above, the sequence indicates a response pattern with wave fronts moving south along the western boundary. The initial boundary current anomaly in its wake extends over the whole water column. It is directed northward at shallow levels (not shown) and southward in the DWBC-level (Fig. 6). During the second year, the signal reaches the equator, where it is converted into equatorial Kelvin waves. Figure 7 shows the velocity anomaly pattern for a level above the Mid-Atlantic Ridge. At greater depths, that is, below $3000 \mathrm{~m}$ (not shown), the situation is somewhat different because the topography blocks eastward propagation of wave fronts along the equator and enables a local adjustment in the deep western basin.

Encountering the eastern wall (in experiment $\mathrm{C} 2$ not later than 2.3 years after switching) the signal excites poleward running boundary waves and northwestward (in the Northern Hemisphere) propagating Rossby waves. A typical signature of these waves is the arc, also found by Gerdes and Wübber (1991), that can be identified between $5^{\circ} \mathrm{N}$ and $10^{\circ} \mathrm{N}$ (Fig. 7). Because of the dominating role of Rossby waves in the latter phase, the adjustment time for a new dynamic quasi equilibrium should, as in the case of a winddriven spinup (Anderson and Killworth 1977), be governed by the timescale of waves crossing the Atlantic, that is, 10-20 years in the midlatitude North Atlantic, consistent with the results of both the low- and high-resolution model cases.

\section{Large-scale circulation and heat transport in different dynamic quasi equilibria}

The temporal behavior examined in the previous section suggests that the final states of experiments $\mathrm{Cl}$, $\mathrm{C} 2$, and $\mathrm{C} 3$, as well as the high-resolution reference case (experiment 4), can be considered to be in neardynamic quasi equilibrium with the thermohaline fluxes specified at the surface and the boundaries. As already noted, neither model is in full thermodynamic equilibrium. Temperature, salinity, and, in turn, the velocity field are still evolving on a much longer timescale given by the weak advective and diffusive processes in the deep ocean interior. After a few decades of integration the deep $\theta$ and $S$ fields are still reflecting the start conditions, except in regions of strong advective processes or convective activity. In the following, the structure of the deep circulation and overturning in the final states of the experiments shall be examined for the effects of the different northern boundary conditions.

The annual mean meridional volume transport streamfunction (Fig. 8) exhibits qualitatively similar structures in all experiments. The main features differ only quantitatively and in their spatial extent and po-

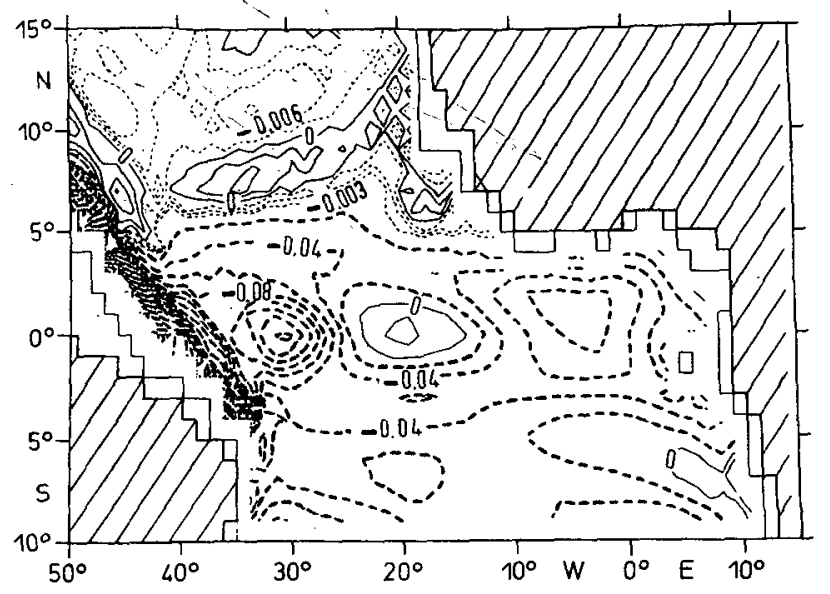

FIG. 7. Zonal velocity anomalies $\left(\mathrm{cm} \mathrm{s}^{-1}\right)$ in experiment $\mathrm{C} 2$ (difference between $\mathrm{C} 2$ and the reference experiment $\mathrm{Cl}$ ) at $1125-\mathrm{m}$ depth, year 2.6 after the change of the northern boundary condition. General contour interval is $0.02 \mathrm{~cm} \mathrm{~s}^{-1}$; it is decreased to $0.003 \mathrm{~cm} \mathrm{~s}^{-1}$ for values greater than -0.009 , north of about $5^{\circ} \mathrm{N}$.

sition. The major overturning cell is centered between 1000 and $2000 \mathrm{~m}$ depth and extends over the entire latitudinal range of the model. Its lower branch accounts for the southward transport of North Atlantic Deep Water (NADW). It is driven by the watermass conversion in the northern and southern boundary zones and by deep winter convection in the subpolar North Atlantic, especially in the Labrador Sea. The NADW cell is underridden by an Antarctic Bottom Water ( AABW) cell, originating in the deepest part of the southern buffer zone and spreading northward up to a maximum latitude of $45^{\circ} \mathrm{N}$. (Parts of the AABW extend farther north, which cannot be seen in the zonally integrated meridional overturning streamfunction.) In the surface layers, there is a system of shallow, winddriven cells. Ekman divergence at the equator forces upwelling of more than $30 \mathrm{~Sv}$. Ekman convergence around $25^{\circ} \mathrm{N}$ results in a downwelling of about $18 \mathrm{~Sv}$.

In the non-eddy-resolving reference experiment $\mathrm{Cl}$, the maximum overturning ( $17 \mathrm{~Sv}$ ) of the NADW cell is found at $44^{\circ} \mathrm{N}$ (Fig. 8a). There is a sinking of about $13 \mathrm{~Sv}$ in the northern buffer zone, north of $60^{\circ} \mathrm{N}$, and $4 \mathrm{~Sv}$ between $60^{\circ}$ and $44^{\circ} \mathrm{N}$. The southward NADW branch extends down to about $3500 \mathrm{~m}$ in the subpolar and to $3200 \mathrm{~m}$ in the subtropical North Atlantic. The AABW cell carries about $4 \mathrm{~Sv}$. In the high-resolution reference case (experiment 4 , Fig. $8 \mathrm{~d}$ ) the maximum overturning (12 Sv) and the vertical extent of the NADW cell $(2500 \mathrm{~m})$ are smaller than in the coarseresolution case. The weaker NADW cell may partly be explained by the narrower, less effective restoring zones at the northern and southern boundary.

The main effects of the core of colder water $\left(0^{\circ} \mathrm{C}\right.$ instead of $3^{\circ} \mathrm{C}$ ) in the northern restoring zone of experiment $\mathrm{C} 2$, are a vertical widening and increased 

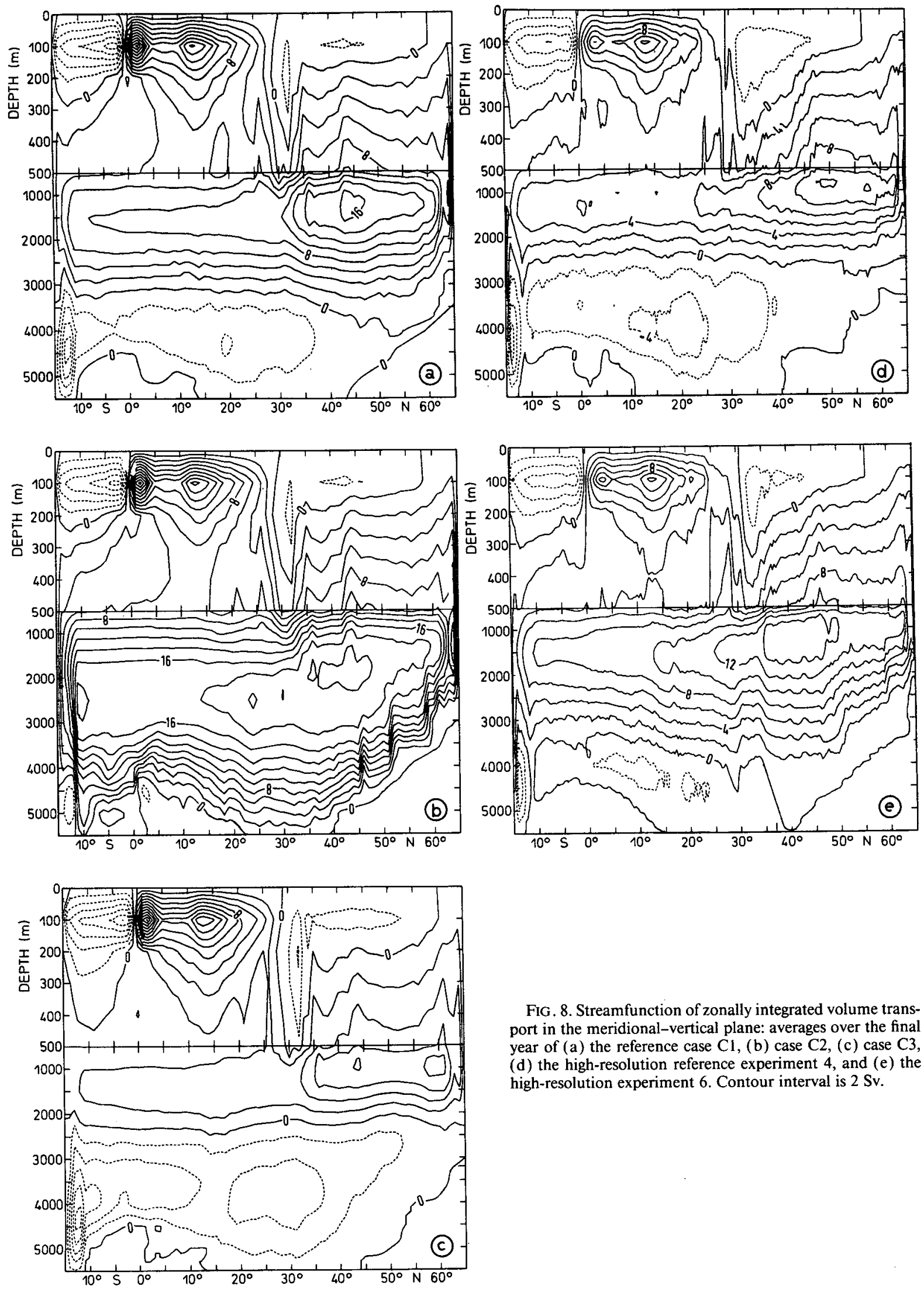

FIG. 8. Streamfunction of zonally integrated volume transport in the meridional-vertical plane: averages over the final year of (a) the reference case $\mathrm{C1}$, (b) case $\mathrm{C2}$, (c) case $\mathrm{C} 3$, (d) the high-resolution reference experiment 4 , and (e) the high-resolution experiment 6 . Contour interval is $2 \mathrm{~Sv}$. 
transport of the NADW cell (Fig. 8b). The cell's core is shifted downward to depths between 2000 and 2500 $\mathrm{m}$. The maximum transport increases to $21 \mathrm{~Sv}$ at about $43^{\circ} \mathrm{N}$; the additional transport of $4 \mathrm{~Sv}$ compared to experiment $\mathrm{Cl}$ is due to enhanced downwelling in the northern boundary zone. Less water is rising in midlatitudes $(2 \mathrm{~Sv})$. Thus, the southward transport of NADW in tropical latitudes increases from about $8 \mathrm{~Sv}$ (experiment $\mathrm{C} 1$ ) to $16 \mathrm{~Sv}$ (experiment $\mathrm{C} 2$ ). The zonally integrated transport of the NADW cell now extends down to the bottom, except south of $15^{\circ} \mathrm{N}$, where a remnant of the AABW cell is present between 4500 and $5500 \mathrm{~m}$. As will be shown later (Fig. 10), the AABW has been pushed back only in the western basin of the North Atlantic. The corresponding high-resolution experiment (experiment 6) does not show a smooth adjustment to a new dynamic quasi equilibrium; especially in the tropics, there are strong interannual oscillations in the streamfunction time series (see section 3, Fig. 5). The annual mean overturning pattern of the last model year (Fig. 8e) therefore represents a snapshot near the end of the dynamic adjustment process. The tendencies are similar as in the coarse-resolution case: the overturning of the upper cell and its vertical extent are increased throughout the model domain, while the AABW cell is reduced in transport and spatial extent.

In the spindown experiment $\mathrm{C} 3$, where surface cooling and boundary restoring below $700 \mathrm{~m}$ in the subpolar North Atlantic were skipped, the main overturning cell (Fig. 8c) becomes distinctly weaker than in experiment $\mathrm{C} 1$ : the maximum transport has decreased from $17 \mathrm{~Sv}$ (experiment $\mathrm{Cl}$ ) to $8 \mathrm{~Sv}$ (experiment $\mathrm{C} 3$ ) of which $7 \mathrm{~Sv}$ takes place within the northern boundary zone caused by the continued restoring to the Levitus climatology above $700 \mathrm{~m}$. The weakened NADW cell goes along with an increased transport and extent of the AABW cell. The interface between the NADW cell and the AABW cell is lifted to about $2300 \mathrm{~m}$. Similar effects on the relative strengths of the two overturning cells can be seen in the CME sensitivity studies of Holland and Bryan (1994) and in the experiments of Maier-Reimer et al. (1993) where the sensitivity to the surface heat flux was studied.

A detailed, quantitative validation of the overturning structures in the models is difficult. Only a few transatlantic sections are presently available. Roemmich and Wunsch (1985) show profiles of geostrophic transport across $36^{\circ} \mathrm{N}$ that indicate two maxima in the southward flow at $1700 \mathrm{~m}$ and between 2500 and $4000 \mathrm{~m}$ (Fig. 9 ). The upper one is associated with the Labrador Sea Water (upper NADW) and the lower with the overflow water originating north of Iceland (lower NADW). The transport in the upper layers above $1200 \mathrm{~m}$ is directed to the north. The influence of AABW is represented by the northward transport below $4300 \mathrm{~m}$.
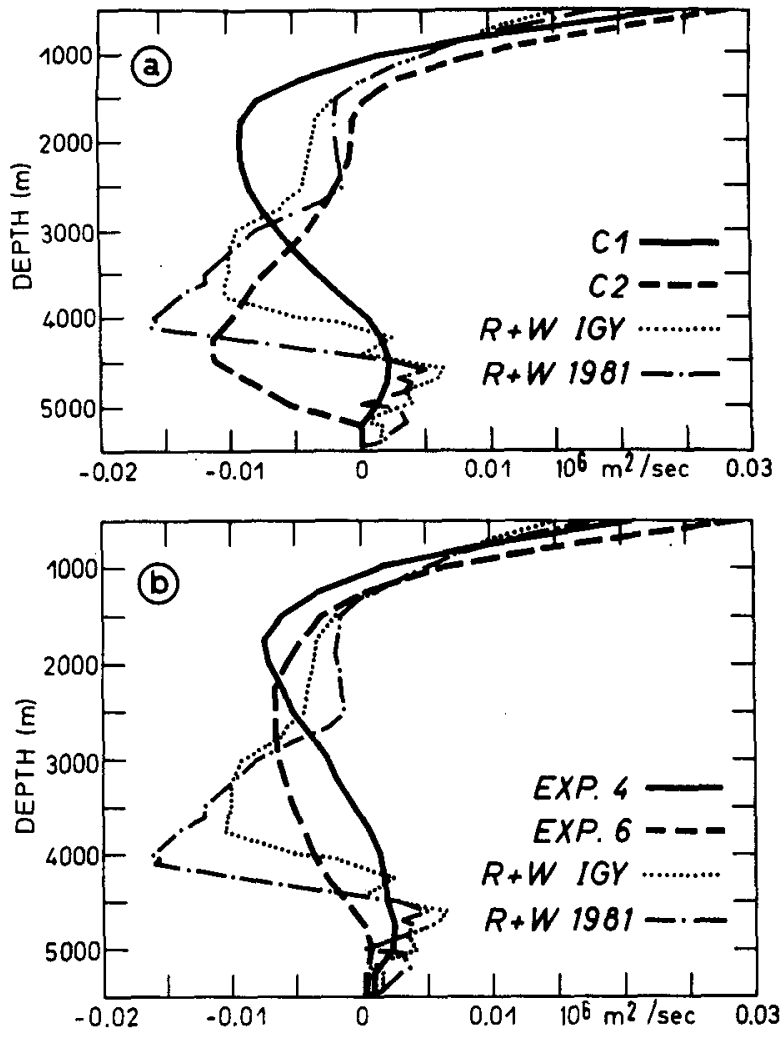

FIG. 9. Observed geostrophic northward transport per unit depth at $36^{\circ} \mathrm{N}$ from Roemmich and Wunsch (1985) $(\mathrm{R}+\mathrm{W})$ and the corresponding annual mean of zonally integrated, northward model transport per unit depth for (a) cases $\mathrm{Cl}$ and $\mathrm{C} 2$ and (b) the highresolution experiments 4 and 6 .

As the model counterpart to the observed profiles, we consider the profiles of total volume transport per unit depth below the surface Ekman layers (Fig. 9). The reference states of both coarse- and high-resolution models (experiment $\mathrm{C} 1$ and experiment 4 ) show only one southward maximum at $1700-\mathrm{m}$ depth, corresponding to the upper NADW range, with a stronger than observed transport. The transport of lower NADW is significantly underrepresented in these reference cases, indicating a lack of thermohaline forcing for that range, consistent with the missing core of dense overflow water in the northern restoring zone. Due to the too low density, the northern boundary condition probably contributes to the forcing of the transport in the upper NADW range.

In the coarse-resolution experiment with a dense core of DSOW in the restoring zone (experiment C2), the vertical profile changes distinctly (Fig. 9a). A weak southward maximum remains at $1700 \mathrm{~m}$, whereas a new one has evolved around $4500 \mathrm{~m}$. The zonally integrated flow is actually reversed here. It mainly reflects the reversed velocities in the deep western basin (Fig. 10 ), where the northward flow of $A A B W$ in experiment 

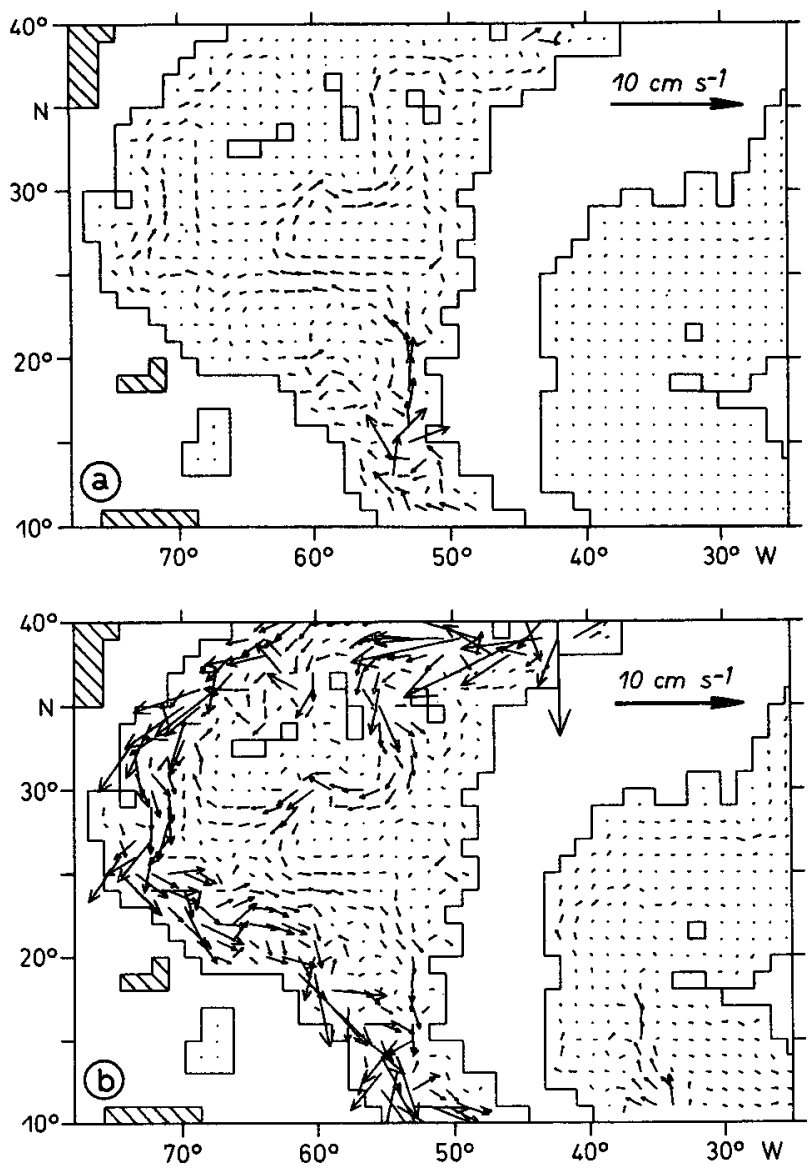

FIG. 10. Mean horizontal velocity in 4375-m depth in the final year of (a) case $\mathrm{Cl}$ and (b) case $\mathrm{C} 2$.

C1 is replaced by a strong southward flow of lower NADW in experiment C2. Thus, a change from climatological to actual section data in the northern boundary zone leads to a dramatic alteration of the deep flow structure. In experiment $\mathrm{C} 2$, the upper maximum seems to be already too weak, compared to the observed profile of Roemmich and Wunsch (1985). Obviously, the relative weight of the two southward maxima is strongly dependent on the relative strength of the thermohaline fluxes at the surface (responsible for deep-water formation in the subpolar North Atlantic) and in the restoring zone to the east of Greenland (representing the effect of convection in the Nordic Seas). A better representation of the observed transports would require considerable fine tuning (and knowledge) of these fluxes.

The change in the transport profile is less pronounced in the high-resolution case (Fig. 9b) due to the different efficiencies of thermohaline forcing in the northern buffer zone. However, the principle difference between $\mathrm{C} 2$ and $\mathrm{Cl}$ can also be seen between experiment 6 and 4: a weakening of the upper southward transport maximum and a strengthening of the transport in the lower NADW range.

During and after the establishment of the new advective regime in $\mathrm{C} 2$, colder water from the north begins to enter the deep western basin. For example, the mean potential temperature in the area $81^{\circ}$ to $45^{\circ} \mathrm{W}$ and $10^{\circ}$ to $45^{\circ} \mathrm{N}$ below 1000 -m depth decreases from $3.28^{\circ} \mathrm{C}$ in $\mathrm{C} 1$ to $3.10^{\circ} \mathrm{C}$ in $\mathrm{C} 2$. The distinctly changed flow structure of $\mathrm{C} 2$ and, less important, the small decrease of potential temperature in the deep western basin cause a substantial change in the northward heat transport (Fig. 11a). Experiment $\mathrm{C} 1$ shows a maximum of $0.82 \mathrm{PW}$ near $32^{\circ} \mathrm{N}$. The enhanced transport of the NADW cell in $\mathrm{C} 2$ corresponds to a distinctly enhanced northward heat transport throughout the model domain, with a maximum of $1.05 \mathrm{PW}$. The northward heat transport of $\mathrm{C} 3$ is on average about $0.3 \mathrm{PW}$ less than that of $\mathrm{Cl}$.

The heat transport in the final year of the high-resolution experiment 6 shows a similar tendency as $C 2$. Compared to experiment 4 , the heat transport is enhanced over the whole model domain (Fig. 1lb). The maximum increases from $0.76 \mathrm{PW}$ (experiment 4 ) to $0.93 \mathrm{PW}$ (experiment 6).
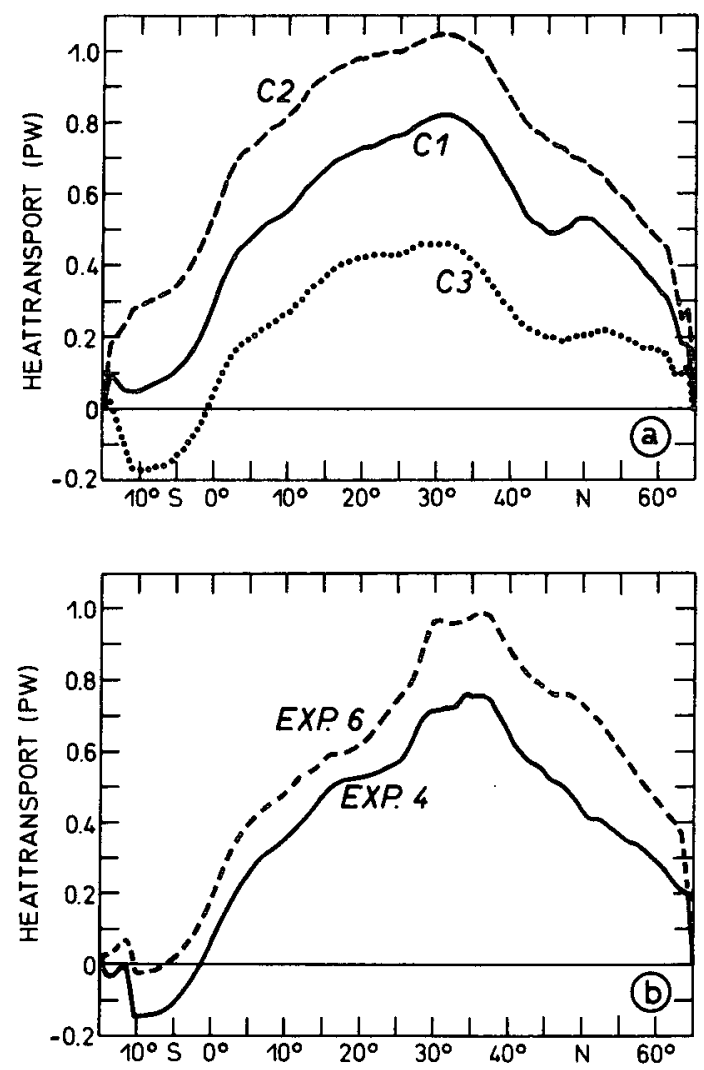

FIG. 11. Annual mean northward heat transport vs latitude for (a) the coarse-resolution experiments $\mathrm{C} 1, \mathrm{C} 2$, and $\mathrm{C} 3$ and (b) the high-resolution cases experiments 4 and 6. 
Horizontal and meridional circulation are not independent of each other. Interaction of the deep thermohaline-driven flow and bottom topography can lead to significant bottom pressure torques that affect the vertically integrated circulation. The effect was demonstrated by Holland (1973) for an idealized ocean basin. Bryan et al. (1994) discuss its implications for the structure of the mean horizontal mass transport in the high-resolution CME experiments. The analogous term in the vorticity equation for the depth-averaged flow is represented by the Joint Effect of Baroclinicity and Relief (JEBAR).

The barotropic vorticity equation of the depth-averaged flow,

$$
\begin{aligned}
\frac{\partial}{\partial t} \nabla \cdot \frac{1}{H} & \nabla \psi=\left(\nabla \frac{f}{H} \times \nabla \psi\right) \cdot \mathbf{e}_{z} \\
& -\left(\nabla \frac{1}{H} \times \nabla \int_{-H}^{0} \frac{\rho}{\rho_{0}} g z d z\right) \cdot \mathbf{e}_{z}+F^{\mathrm{turb}}+F^{\mathrm{adv}},
\end{aligned}
$$

(e.g., see Willebrand 1989) gives the balance between temporal change of relative vorticity (left-hand side), planetary vorticity advection (first term on the righthand side), JEBAR ( second term on the right-hand side), turbulent and advective transports of vorticity. JEBAR represents a forcing term of the barotropic vorticity budget, which transmits baroclinic information to the barotropic streamfunction field. A detailed discussion of the vorticity budget is beyond the scope of the present paper; however, the role of JEBAR can be illuminated by examining the difference in the annual mean streamfunction patterns for the final states of $\mathrm{C} 2$ and $\mathrm{C} 1$.

The streamfunction $\psi$ of the reference experiment Cl (Fig. 12a) shows the familiar gyre pattern in the subtropics and in the subpolar region along with weaker cells in the equatorial region. The horizontal transport of $\mathrm{C} 2$ (Fig. 12b) is generally stronger. As indicated by $\psi(\mathrm{C} 2)-\psi(\mathrm{C} 1)$ (Fig. 12c), the differences are mainly confined to the western part of the basin and to the equatorial region. The maximum transport at $30^{\circ} \mathrm{N}$ increases from 40 to $60 \mathrm{~Sv}$ as an expression of the stronger, deeper, and eastward displaced DWBC core and an increased thermohaline-driven part of the upper western boundary current. For the same reasons, a local cell around $41^{\circ} \mathrm{N}, 46^{\circ} \mathrm{W}$ is established and the streamfunction south of Newfoundland and along the North Atlantic Current is reduced. In Fig. 13 the JEBAR difference between the two cases is displayed. Similar to the change of the barotropic streamfunction, maximum amplitudes are confined mainly to the western boundary and to the western part of the subpolar gyre, that is, the regions.where changes in the deep flow field are strongest. In the tropics, differences in JEBAR become small, indicating that higher order terms in the vorticity balance play a more fundamental role in determining the barotropic streamfunction.
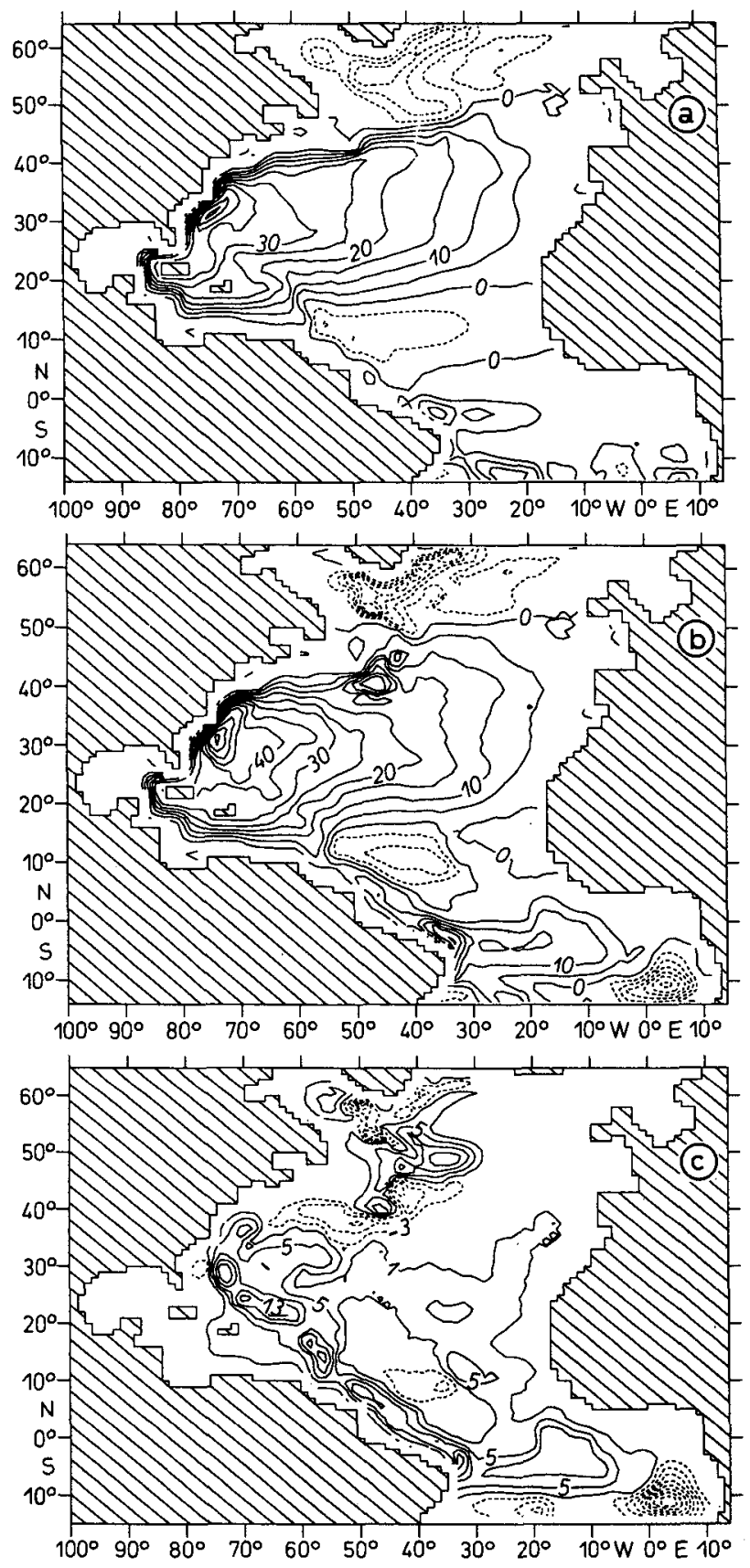

FIG. 12. Annual mean barotropic streamfunction (in Sv) for (a) case $\mathrm{C} 1,(\mathrm{~b})$ case $\mathrm{C} 2$ (both contour interval $5 \mathrm{~Sv}$ ), and (c) $\mathrm{C} 2-\mathrm{Cl}$ (contour interval $3 \mathrm{~Sv}$ ).

\section{Summary and conclusions}

The adjustment of the deep ocean circulation to changes in the thermohaline fluxes acting at the sea surface evolves through several stages. The establishment of a thermodynamic equilibrium with prescribed atmospheric boundary conditions takes more than 


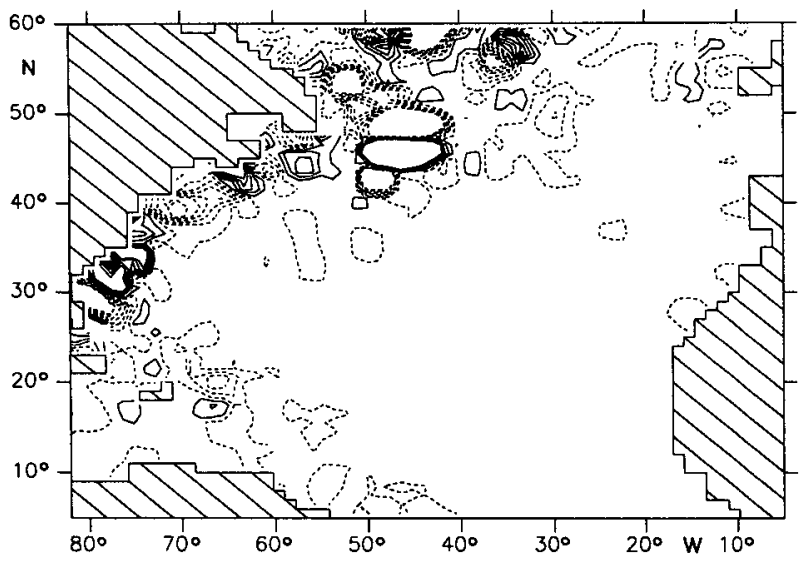

FIG. 13. Annual mean JEBAR(C2) - JEBAR(C1) (in s ${ }^{-2}$ ) (contour interval $\left.0.17 \times 10^{-11} \mathrm{~s}^{-2}\right)$. The displayed range is limited between $-0.869 \times 10^{-11}$ and $0.831 \times 10^{-11} \mathrm{~s}^{-2}$ to avoid optical confusion.

1000 years, a timescale set by the slow advective and diffusive processes of the deep ocean interior. In the present experiments with various versions of the $\mathrm{CME}$ model, we have not been concerned with these longterm aspects of the thermohaline circulation, but with the initial dynamic phase of the adjustment process during the first 1-2 decades and the characteristics of different dynamic quasi-equilibrium states.

A common problem of many numerical models of the large-scale, wind-driven, and thermohaline-driven circulation is a too weak northward heat transport in the subtropical North Atlantic, compared to the observational result of $1.2 \mathrm{PW}$ at $24^{\circ} \mathrm{N}$ (Hall and Bryden 1982). The $1^{\circ}$ version of the CME model in "standard" configuration ( reference solution $\mathrm{C} 1$ ) has a maximum heat transport of $0.82 \mathrm{PW}$, very similar to the Atlantic model of Sarmiento (1986). Both models use a diagnostic zone formulation at the artificial northern and southern boundaries, with a relaxation of model $\theta$ and $S$ to the climatological values as given by Levitus (1982). Similar formulations have been used in the World Ocean model of Semtner and Chervin (1992), as a means to include the effect of the overflow waters. The present experiments show that the missing core of dense DSOW in the Levitus dataset has a devastating effect on the forcing of southward flow in the depth range of lower NADW. The vertical profile of meridional volume transport per unit depth in these experiments differs distinctly from the observational results of Roemmich and Wunsch (1985), who noted a double maximum in the deep-water transport in both the 1957 and the 1981 data. Two distinct cores of deep southward flow along the continental slope of the subtropical and tropical North Atlantic are found also in Freon concentrations (Fine and Molinari 1988; Rhein et al. 1994) and direct current measurements (Schott et al. 1993). The transition to a restoring condition based on actual section data from the Denmark Strait results in a strongly enhanced overturning (from 17 to $21 \mathrm{~Sv}$ at the maximum, and from 8 to $16 \mathrm{~Sv}$ in the Tropics) and leads to a pronounced maximum at the lower NADW level in the volume transport profile of the $1^{\circ}$ model. The change in overturning corresponds to an increase of the maximum northward heat transport from 0.83 to $1.05 \mathrm{~Sv}$. In the high-resolution version of the model, with narrower and apparently less effective restoring zones, the maximum heat transport has increased from $0.76 \mathrm{PW}$ to $0.93 \mathrm{PW}$ in the 14 th year after the switch to the actual section data.

The stronger southward transport at the lower NADW level is associated with a vertical expansion and intensification of the DWBC, and a weakening and southward displacement of the AABW cell. As an effect of the interaction of the altered deep flow field with the bottom topography (given by the JEBAR term in the barotropic vorticity equation), there are also distinct changes in the horizontal circulation. While the transport of the subpolar gyre is intensified throughout the western basin, the subtropical gyre is affected mainly near the western boundary. This behavior is consistent with the analysis of the vorticity balance of the high-resolution CME cases by Bryan et al. (1994), who found a strong influence of the bottom torques induced by the thermohaline-driven deep flow throughout the subpolar gyre, while linear Sverdrup dynamics could explain much of the barotropic transport in the subtropical gyre, away from the western boundary. Strong effects of a changed meridional overturning on the horizontal gyre circulations were also obtained by Gerdes and Köberle (1994) in a model study concerned with the influence of different surface boundary conditions in the Greenland-Iceland region. However, while their model results indicate a strengthening of the gyre transport in a similar way as in the $\mathrm{CME}$, there are some local, but important differences, for example, in the path of the Gulf Stream. In the model of Gerdes and Köberle (1994), a stronger thermohaline cell leads to a southward shift of the current axis and separation from the coast near Cape Hatteras. In the CME cases a similar tendency can be seen for the Gulf Stream downstream of Cape Hatteras, but neither the $1^{\circ}$ nor the $1 / 3^{\circ}$ version show a salutary influence on the deleterious separation behavior that characterizes all high-resolution cases (Bryan and Holland 1989; Beckmann et al. 1994). The different behavior suggests that higher-order dynamics could play an essential role at this point, possibly leading to a strong, but yet unknown effect of the particular numerical implementation of advective and diffusive processes.

We believe that the dynamic adjustment process of the deep ocean to a prescribed thermohaline forcing is not only of relevance for understanding the spinup mechanism in models like the CME, but may also be 
of importance for the ocean's response to interannual changes in deep convection and water mass conversion. There is growing observational evidence of interannual variations in deep-water production rates and water mass properties of the subpolar North Atlantic.

Tracer observations in the Greenland Sea have shown a significantly reduced deep-water formation in the 1980s (Rhein 1991; Schlosser et al. 1991), leading to a slow warming and salinification of the deep water (GSP Group 1993). Variations in the $T-S$ properties of the overflow waters have been observed in the Labrador Sea (Lazier 1988). A significant renewal of Labrador Sea Water (LSW) occurs in only $60 \%$ of the winters (Clarke and Gascard 1983). However, the dynamic effect of such variations in the source water masses for NADW on the large-scale circulation is largely unknown. Current meter records from the continental slope off eastern Greenland indicated only little seasonal and year-to-year changes (Dickson et al. 1990). On the other hand, there are indications for substantial deep circulation changes in the midlatitude North Atlantic. The Roemmich and Wunsch (1985) analysis of the transatlantic sections taken during the IGY (1957) and 1981 suggests a pronounced shift in the southward transport profile from upper to lower NADW, and Lippert (1992) noted that mean flow directions in the deep Sargasso Sea in the 1980s were opposite to the 1970s. Large-scale changes in the North Atlantic temperature and salinity distributions had been found for the pentads 1955-59 and 1970-74 (Levitus 1989a,b). Using a diagnostic model to examine the relevance of these density differences for the North Atlantic circulation, Greatbatch et al. (1991) found a $30 \mathrm{~Sv}$ reduction in the Gulf Stream transport in 1970-74 compared to 1955-59, and attributed the changes to a weakening of the thermohaline circulation. Evidence for rapid, that is, decadal, changes in circulation patterns also comes from geological and paleoceanographic observations. Oxygen isotope records from the Greenland ice sheet show series of abrupt transitions between different climatic states during much of the last glacial and preceding interglacial (GRIP 1993). Sediment records from the subpolar North Atlantic suggest, at least for the events that occurred during the last deglaciation, a correlation with changes in the North Atlantic circulation pattern (Boyle and Keigwin 1987; Lehman and Keigwin 1992).

While the numerical experiments reported here are not intended as a simulation of actual, low-frequency variations in the ocean circulation, the results nevertheless illuminate basic characteristics of the dynamic response of the ocean to changes in high-latitude thermohaline forcing. The initial response to a step-function change in the high-latitude, thermohaline boundary conditions unfolds in two stages. In the primal stage, the signal is mediated rapidly by wave processes along the deep western boundary, leading to changes in the western boundary current system. The transmission of the signal to the eastern boundary by Kelvin waves along the equator sets up the second stage of the dynamic response, the baroclinic adjustment of the ocean interior governed by baroclinic Rossby waves. The dynamic response in the present complex model of the wind- and thermohaline-driven circulation in realistic North Atlantic bathymetry thus proceeds, in principle, in a similar way as in the idealized models of Kawase (1987), Suginohara and Fukasawa (1988), and Kawase et al. (1992). There are differences, however, concerning the timescale of the initial response. The behavior during the first months depends on the horizontal resolution of the numerical model: in the non-eddy-resolving version of the model the wave fronts reach the subtropical North Atlantic after about one year, the equator after about two years. In the high-resolution version the response starts more abruptly; first effects at the equator are seen already after a few months. The changes in the deep western boundary current system are associated with significant changes in meridional transport, leading to a rapid signal in the zonally integrated overturning and, correspondingly, in the meridional heat transport. The difference in the initial response time during the first four years must be due to the different numerical representation of the wave processes along the continental shelf: contrary to the coarse-grid case, the finer grid enables a better resolution of hybrid shelf waves, resulting in a faster signal transmission along the boundary.

As in the earlier, idealized model studies, the adjustment to a new dynamic quasi equilibrium seems to be governed by the baroclinic Rossby waves, and takes about $10-15$ years in the $1^{\circ}$ model. The $1 / 3^{\circ}$ model could not be integrated for more than 14 years due to the heavy demands on computer time. In that case the adaptation to a new dynamic equilibrium is accompanied by intense interannual fluctuations in the volume transport, making quantitative conclusions about adjustment timescales more difficult. However, we do not expect the phase speed of the gravest baroclinic Rossby wave modes, which are well resolved in either version, to differ very much between the two cases (e.g., see Wajsowicz 1986).

From the present experiments one cannot tell at which grid size the representation of these boundary wave phenomena begins to converge. However, the present results do suggest that the very coarse grids used in today's coupled ocean-atmosphere models disable the fast wave modes and are therefore likely to overestimate the initial response time of the deep ocean circulation to changing surface fluxes. Model simulations of the effect of interannual or decadal variations in the surface conditions over the convection areas of the subpolar North Atlantic could thus critically depend on the grid resolution: the absence of fast waves in coarse-grid ocean models may act like a low-pass 
filter and could distort the response spectrum of the deep ocean circulation to a more red character. This filtering process may suppress the ability of the thermohaline circulation to "feel" fast, say, year-to-year changes in the fluxes and convective activity. On the other hand the dynamic adjustment on the decadal timescale should be much less sensitive to grid resolution and hence a more robust process.

Acknowledgments. We thank F. Bryan and W. Holland for providing the original CME code and A. Beckmann for helpful discussions. This study is supported by the Deutsche Forschungsgemeinschaft, Sonderforschungsbereich 133.

\section{REFERENCES}

Anderson, D. L. T., and P. D. Killworth, 1977: Spin-up of a stratified ocean, with topography. Deep-Sea Res., 24, 709-732.

Beckmann, A., C. W. Böning, C. Köberle, and J. Willebrand, 1994: Effects of increased horizontal resolution in a simulation of the North Atlantic Ocean. J. Phys. Oceanogr., 24, 326-344.

Böning, C. W., and P. Herrmann, 1994: On the annual cycle of poleward heat transport in the ocean: Results from high-resolution modeling of the North and Equatorial Atlantic. J. Phys. Oceanogr., 24, 91-107.

—, R. Döscher, and R. G. Budich, 1991: Seasonal transport variation in the western subtropical North Atlantic: Experiments with an eddy-resolving model. J. Phys. Oceanogr., 21, 12711289.

Boyle, E. A., and L. Keigwin, 1987: North Atlantic thermohaline circulation during the past 20,000 years linked to high-latitude surface temperature. Nature, 330, 35-40.

Bryan, F., 1987: Parameter sensitivity of primitive equation ocean general circulation models. J. Phys. Oceanogr., 17, 970-985.

- and W. R. Holland, 1989: A high resolution simulation of the wind and thermohaline-driven circulation in the North Atlantic Ocean. Parametrization of Small-Scale Processes. Proc. Aha Huliko'a Hawaiian Winter Workshop. P. Müller and D. Anderson, Eds., University of Hawaii at Manoa, 99-115.

- C. W. Böning, and W. R. Holland, 1994: On the midlatitude circulation in a high-resolution model of the North Atlantic. $J$. Phys. Oceanogr., 24, in press.

Bryan, K., 1962: Measurements of meridional heat transport by ocean currents. J. Geophys. Res., 67, 3403-3414.

- 1969: A numerical method for the study of the circulation of the world ocean. J. Comput. Phys., 4, 347-376.

Clarke, R. A., and J.-C. Gascard, 1983: The formation of Labrador Sea Water. Part I: Large-scale processes. J. Phys. Oceanogr., 13, 1764-1778.

Colin de Verdiére, A., 1988: Buoyancy driven planetary flows. $J$. Mar. Res., 46, 215-265.

Cox, M. D., 1984: A primitive equation, 3-dimensional model of the ocean. Tech. Rep. 1, Ocean Group, Geophysics and Fluid Dynamics Laboratory, Princeton, NJ.

- 1987: An eddy-resolving numerical model of the ventilated thermocline: Time dependence. J. Phys. Oceanogr., 17, 10441056.

Davey, M. K., W. W. Hsieh, and R. C. Wajsowicz, 1983: The free Kelvin wave with lateral and vertical viscosity. J. Phys. Oceanogr., 13, 2182-2191.

Dickson, R. R., E. M. Gmitrowicz, and A. J. Watson, 1990: Deepwater renewal in the northern North Atlantic. Nature, 344, 848850.

Fine, R. A., and R. L. Molinari, 1988: A continuous deep western boundary current between Abaco $\left(26.5^{\circ} \mathrm{N}\right)$ and Barbados $\left(13^{\circ} \mathrm{N}\right)$. Deep-Sea Res., 35, 1441-1450.
Gerdes, R., and C. Wübber, 1991: Seasonal variability of the North Atlantic Ocean-a model intercomparison. J. Phys. Oceanogr., 21, 1300-1322.

- and C. Köberle, 1994: On the influence of DSOW in a numerical model of the North Atlantic general circulation. J. Phys. Oceanogr., submitted.

- C. Köberle, and J. Willebrand, 1991: The role of numerical advection schemes in general circulation models. Climate Dyn., 5, 211-226.

Gordon, A. L., 1986: Interocean exchange of thermocline water. $J$. Geophys. Res., 91, 5037-5046.

Greatbatch, R. J., A. F. Fanning, and A. D. Goulding, 1991: A diagnosis of interpendental circulation changes in the North Atlantic. J. Geophys. Res., 96, 22 009-22 023.

GRIP, 1993: Climate instability during the last interglacial period recorded in the GRIP ice core. Nature, 364, 203-207.

GSP Group, 1993: Greenland Sea Project. Eos, Trans. Amer. Geophys. Union, $71(24), 750-755$.

Hall, M. M., and H. L. Bryden, 1982: Direct estimates and mechanisms of ocean heat transport. Deep-Sea Res., 29, 339-360.

Han, Y.-J., 1984: A numerical World Ocean general circulation model. Part II: A baroclinic experiment. Dyn. Atmos. Oceans, 8, 141-172.

Holland, W. R., 1973: Baroclinic and topographic influences on the transport in western boundary currents. Geophys. Fluid Dyn., 4, 187-210.

$\longrightarrow$, and F. O. Bryan, 1994: Sensitivity studies on the role of the ocean in climate change. Ocean Processes in Climate Dynamics: Global and Mediterranean Examples. P. Malanotte-Rizzoli and A. R. Robinson, Eds., NATO ASI Proc., Kluwer, in press.

Hsieh, W. W., M. K. Davey, and R. C. Wajsowicz, 1983: The free Kelvin wave in finite-difference numerical models. J. Phys. Oceanogr., 13, 1383-1397.

Huthnance, J. M., 1978: On coastal trapped waves: Analysis and numerical calculation by inverse iteration. J. Phys. Oceanogr., 8, 74-92.

Isemer, H. J., and L. Hasse, 1987: The Bunker Climate Atlas of the North Atlantic Ocean. Vol. 2, Air-Sea Interactions, SpringerVerlag, $256 \mathrm{pp}$.

Kawase, M., 1987: Establishment of deep ocean circulation driven by deep-water production. J. Phys. Oceanogr., 17, 2294-2317.

- - L. M. Rothstein, and S. R. Springer, 1992: Encounter of a deep western boundary current with the equator: A numerical spin-up experiment. J. Geophys. Res., 97(C4), 5447-5463.

Lazier, J. R. N., 1988: Temperature and salinity changes in the deep Labrador Sea, 1962-1986. Deep-Sea Res., 35(8), 1247-1253.

Lehman, S. J., and L. D. Keigwin, 1992: Sudden changes in North Atlantic circulation during the last deglaciation. Nature, 356, 757-762.

Levitus, S., 1982: Climatological Atlas of the World Ocean. NOAA Prof. Paper 13, U.S. Govt. Printing Office, Washington, DC, $173 \mathrm{pp}$.

_- 1989a: Interpendental variability of temperature and salinity at intermediate depths of the North Atlantic Ocean, 1970-1974 versus 1955-1959. J. Geophys. Res., 94(C5), 6091-6131.

- $1989 \mathrm{~b}$ : Interpendental variability of temperature and salinity in the deep North Atlantic, 1970-1974 versus 1955-1959. J. Geophys. Res., 94(C11), 16 125-16 131.

Lippert, A., 1992: Beobachtungen langzeitlicher Änderungen der Tiefenzirkulation im Nordatlantik (extended abstract). Ann. Meteor., 27, 220-221.

Maier-Reimer, E., U. Mikolajewicz, and K. Hasselmann, 1993: Mean circulation of the Hamburg LSG OGCM and its sensitivity to the thermohaline surface forcing. J. Phys. Oceanogr., 23, 731757.

Marotzke, J., and J. Willebrand, 1991: Multiple equilibria of the global thermohaline circulation. J. Phys. Oceanogr., 21, 13721385 . 
Molinari, R. L., R. A. Fine, and E. Johns, 1992: The deep western boundary current in the western tropical North Atlantic Ocean. Deep-Sea Res., 39(11/12), 1967-1984.

Mysak, L. A., 1980: Recent advances in shelf wave dynamics. Rev. Geophys. Space Phys., 18, 211-241.

Redi, M. H., 1982: Oceanic isopynal mixing by coordinate rotation. J. Phys. Oceanogr., 12, 1154-1158.

Rhein, M., 1991: Ventilation rates of the Greenland and Norwegian Seas from distributions of the chlorofluoromethanes F11 and F12. Deep-Sea Res., 38, 485-503.

- L. Stramma, and U. Send, 1994: The Atlantic deep western boundary current: Water masses and transports near the equator. $J$. Geophys. Res., in press.

Roemmich, D., and C. Wunsch, 1985: Two transatlantic sections: Meridional circulation and heat flux in the subtropical North Atlantic Ocean. Deep-Sea Res., 32, 619-664.

Sarmiento, J. L., 1986: On the North and tropical Atlantic heat balance. J. Geophys. Res., 91, $11677-11689$.

Schlosser, P., G. Bönisch, M. Rhein, and R. Bayer, 1991: Reduction of deep water formation in the Greenland Sea during the 1980s: Evidence from tracer data. Science, 251, 1054.

Schmitz, W. J., Jr., and P. L. Richardson, 1991: On the sources of the Florida Current. Deep-Sea Res., 38(Suppl. 1), S389-S409.
Schott, F., J. Fischer, J. Reppin, and U. Send, 1993: Mean and seasonal currents and transports at the western boundary of the equatorial Atlantic. J. Geophys. Res., 98, 14 353-14 368.

Semtner, A. J., and R. M. Chervin, 1992: Ocean general circulation from a global eddy-resolving model. J. Geophys. Res., 97, 5493-5550.

Smethie, W. M., Jr., and J. H. Swift, 1989: The Tritium:Krypton85 age of Denmark Strait overflow water and Gibbs Fracture Zone water just south of Denmark Strait. J. Geophys. Res., 94(C6), 8265-8275.

Stommel, H., and A. B. Arons, 1960: On the abyssal circulation of the world ocean-I. Stationary planetary flow patterns on a sphere. Deep-Sea Res., 6, 140-154.

Suginohara, N., and M. Fukasawa, 1988: Set-up of the deep circulation in multi-level numerical models. J. Oceanogr. Soc. Japan, 44, 315-336.

Wajsowicz, R. C., 1986: Free planetary waves in finite-difference numerical models. J. Phys. Oceanogr., 16, 773-789.

Weaver, A. J, and E. S. Sarachik, 1991: The role of mixed boundary conditions in numerical models of the oceans climate. J. Phys. Oceanogr., 21, 1470-1493.

Willebrand, J., 1989: General circulation dynamics. Landolt-Börnstein, Numerical Data and Functional Relationships in Science and Technology, New Series V/3b, J. Sündermann, Ed., Springer-Verlag, 123-150. 